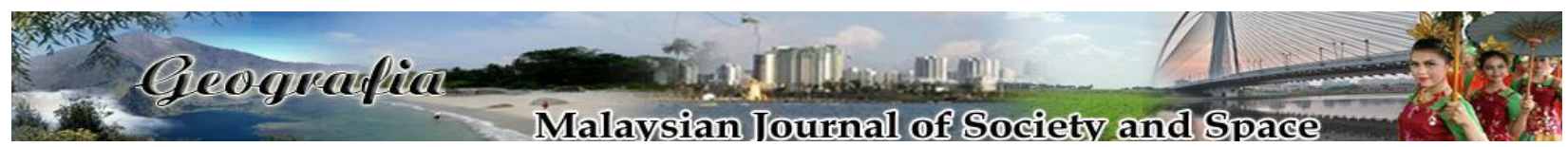

\title{
Cultural tolerance, positive relationships and well-being in Malaysian multicultural communities
}

\author{
Mitshel Lino, Intan Hashimah Mohd Hashim \\ School of Social Sciences, Universiti Sains Malaysia. Penang, Malaysia. \\ Correspondence: Mitshel Lino (email: mitshel.mitshel@gmail.com)
}

Received: 01 October 2020; Accepted: 24 November 2020; Published: 29 November 2020

\begin{abstract}
Taking a positive psychology perspective, this paper focuses on cultural tolerance values, positive relationships, and well-being within multicultural and pluralistic local communities in Malaysia. Participants were $(n=163)$ undergraduates from a Malaysian public university. Eightythree (83) were of ethnic Malay, (69) ethnic Chinese, nine ethnic Indian, and two were ethnic 'others.' Participants were predominantly females (122/74.8\%). Participants answered an online survey comprising of open-ended qualitative questions on cultural tolerance values, positive relationships, and well-being as part of their experience living in multicultural communities. Findings indicated that participants described themselves as highly tolerant; they generally agreed that people should be allowed to practice their culture. They reported open and positive emotions (e.g. curiosity, interest, and gratefulness) and positive reactions (e.g. acceptance and respect) about others who practice different cultures. They also reported positive relationships in their communities, whereby they described the people in the community as well-connected. Using the PERMA model of well-being as the basis of analysis, participants reported a high level of wellbeing across aspects of positive emotions, engagement, relationship, meaning, and accomplishment. This study sheds some lights regarding Malaysians' cultural tolerance values, people's relationships within multicultural communities and community well-being.
\end{abstract}

Keywords: Community well-being, cultural tolerance in Malaysia, Malaysian community, multicultural relationship, PERMA, positive psychology.

\section{Introduction}

As part of a heterogeneous society, Malaysia comprises of people of various ethnicities, religions, languages, and cultures, co-existing within one geographical location (The National Department of Culture and Arts (JKKN), 2018). They live and interact with each other on daily basis. In a heterogeneous society, intercultural interactions are inevitable; hence, interethnic relations are essential and of great national interest (Chang \& Kho, 2017). As such, social 
scientists are interested in the process and mechanism that allows people from diverse backgrounds to co-exist harmoniously, including cultural tolerance.

This interest in intercultural interactions has prompted numerous studies. One such study is KAJIDATA Research (2017). In this study, a nationwide survey to assess Malaysians' support for government initiatives including their perspective on culture, ethnicity, religion, education system, and patriotic value was conducted. The results indicated that $96.9 \%$ are respectful towards different ethnic groups and $92.8 \%$ of Malaysians are proud of their multi-ethnic and multi-cultural society.

Albeit the above results, relationships and interactions among people of different cultural groups in the local communities remain limited. Many Malaysians tend to maintain same-ethnic friendships (Lee, 2017). Widespread power dynamics resulted from racial, ethnic, gender, religious, and socio-economic status differences in close-knitted communities can potentially create a gap among people from different groups (Tajfel, 1974). Lee (2017) suggested several factors may widen the cultural gaps among Malaysian ethnic groups. They include personal choices, religion, language and cultural differences, as well as political manipulations and governmental preferential policies (Lee, 2017).

Despite limited interactions among diverse people, major racial conflicts among Malaysians were rare (Haque, 2003). Different groups, majority or minority, are allowed to practice their cultural values expectations (Ahmad, Salman, Rahim, Pawanteh, \& Ahmad, 2013). Each ethnic group in Malaysia practices different religions, uses different mother tongues, goes to different vernacular/ national schools, and tends to socialise mostly within the same ethnicity. Malaysians, although divided by ethnicities, religions, mother-tongues, and marked physical differences, appeared to live peacefully with each other (Hirschman, 1987). They remained respectful of each other's practices and traditions. We argue this is one of the strengths of Malaysians that is not yet fully explored.

Such a paradox in findings often calls for a more comprehensive understanding of Malaysia's multicultural communities that may not be fully accomplished through a quantitative study. This paper discusses a qualitative study that examined the relations of cultural tolerance values, positive relationships, and well-being in local communities. Exploring these components are important in a multi-group society like Malaysia. It is an opportunity to understand the function of diverse communities and the dynamic of intercultural interactions.

\section{Positive psychology, cultural tolerance, positive relationships, and well-being}

The underlying framework for cultural tolerance, positive relationships, and well-being in the present study is positive psychology. Positive psychology was defined as 'the scientific study of optimal human functioning that aims to discover and promote the factors that allow individuals and communities to thrive' (Seligman \& Csikszentmihalyi, 2000). It was reintroduced by Martin Seligman to provide a more balanced and well-rounded perspective to the problem-oriented approach of traditional psychology (Lopez \& Gallagher, 2009; Snyder, Lopez, \& Pedrotti, 2011).

Positive psychology focuses on the strengths of the individual and community. Presently, we argue that cultural tolerance is part of the community strengths that will allow people to interact more positively and thrive. From social psychology, tolerance can be conceptualised as appreciating differences, adopting a favourable attitude toward outgroups, demonstrating a lack of prejudice, and enduring disagreement and prejudice (Verkuyten, 2010). Due to its novelty, 
this study attempted to operationally define it as an individual's agreement to allow people from different religions/ ethnicities to practice their cultures.

Cultural tolerance can be viewed as one of the attitude constructs. The attitude refers to a psychological tendency to evaluate an entity with a degree of favour or disfavour (Eagly \& Chaiken, 1993). In cultural tolerance, it is an evaluation targeted at the cultural practice of others. Consistent with our operational definition, the agreement is part of the evaluation directed at the cultural behaviours of different groups. An attitude is divided into three distinct components: affect (emotion), behaviour (action), and cognitive (mental attribution towards the attitude object) (Eagly \& Chaiken, 1993; 1995). Presently, cultural tolerance as an attitude towards others' cultures was examined using the same components.

One vital contributor to thriving communities is positive relationships. To establish a healthy relationship, it is important to address the needs and perspectives of everyone (Roffey, 2012). A positive relationship may only result in well-being when nobody controls the relationship for personal interest (Roffey, 2012) and one provides ethical solutions to intercultural conflicts (Kastel, 2012). The definition of positive relationships in positive psychology remains unclear (Ooi \& Hashim, 2018). Presently, it is operationally defined as the ability of the members of multiple cultural groups to have cordial bonds, a sense of connectedness and belongingness, and ethical responses to potential cultural conflicts.

Subjective well-being can be defined as 'a person's cognitive and affective evaluations of his or her life' (Diener, Oishi, \& Lucas, 2009). Social factors such as social adjustment and social support (Larson, 1993), social well-being, social integration, social contribution, social coherence, social actualisation, and social acceptance (Keyes, 1998) play a key role in contributing to subjective well-being. According to well-being theory, five core features are known as PERMA: (i) Positive emotion, (ii) Engagement (flow), (iii) Positive Relationship, (iv) Meaning, and (v) Accomplishment are essential to promote flourishing individuals and societies (Seligman, 2011). This study utilised PERMA to measure participants' well-being in local multicultural communities. We argue that positive relationships in the form of cultural tolerance, contribute to sustainable happiness and communal well-being.

\section{Studies on cultural tolerance}

Cultural tolerance is a relatively new concept in positive psychology. The following discussed the limited literature, particularly those related to positive relationships.

Cultural tolerance values and practices in local communities influenced the relationship of diverse groups. Al Zu'abi (2018) examined the level of tolerance in Arabs' everyday life and economic transformations. Findings suggested low respect and acceptance due to racial affiliation, general attitude, and others. Tolerance existed as a theoretical but not functional concept. Low tolerance had contributed to the increasing gap between the in-group and outgroup, which prevented harmonious coexistence (Al Zu'abi, 2018). This study highlighted the importance of cultural tolerance towards intercultural relationships of community everyday life.

Cultural, ethnic, and religious differences influenced the level of social tolerance in a community. In Poland, Gołębiowska (2009) investigated the level of social tolerance among different ethnic and religious groups towards acceptance of interethnic and interreligious marriage. Ethnic tolerance was higher than religious tolerance. Despite the high likelihood to oppose the idea of interethnic marriages (Jewish and Chinese) for their children, the opposition against inter-religious marriages (Muslim, Jewish, and atheist) was higher (Gołębiowska, 2009). The connection between religious differences and cultural tolerance was presently explored. 
Few studies have focused on cultural tolerance in Malaysia. Some examined the positive relationships but mostly did not include the well-being aspects of multicultural communities, which were presently explored.

Abdul Rahman, Ahmad, Awang and Ahmad (2015) and Abdul Hamid, Ahmad Marzuki, Ahmad and Ishak (2016) investigated tolerance in different contexts, developed and tested instruments. Abdul Rahman et al. (2015) examined patriotism and tolerance level among Malaysian youths, while Abdul Hamid et al. (2016) observed community social capital in Kedah. Both researchers defined and measured tolerance differently. Abdul Rahman et al. (2015) illustrated ethnic tolerance as two interconnected systems, i.e. social connection among diverse individuals affected everyone involved. Measurements included social acceptance, ethnic values, compromise, and absorption (Abdul Rahman et al., 2015). Meanwhile, in Abdul Hamid et al. (2016), tolerance of diversity is an element of community social capital development. Tolerance was measured through socialisation, acceptance, neighbourliness, respect, and comfort living in a diverse community (Abdul Hamid et al., 2016). Social connection and socialisation remain important aspects related to cultural tolerance.

Malaysian local communities can be either ethnically heterogeneous or homogenous, depending upon the locations. A quantitative study was conducted among diverse Malaysian undergraduates from multicultural communities to develop an index on ethnic tolerance (Wan Husin, Abdul Halim, \& Zul Kernain, 2020). The majority had friends from interethnic and interreligious communities and involved in community activities. They were highly tolerant; many agreed with an affirmative attitude to raise ethnic and religious tolerance levels (Wan Husin et al., 2020). Tolerance values are connected to multicultural communities, intercultural and inter-religious friendships.

One way to study interactions within a community is by looking at neighbourhood associations or Rukun Tetangga (RT). RT was established to build unity and harmony within Malaysian local communities (Ahmad Farouk \& Abu Bakar, 2007). It promotes neighbourliness (Ahmad Sabri \& Mohammad, 2016) and unity (Khairi \& Mior Jamaluddin, 2017). RT builds trust, partly by fostering direct interaction and cooperation among residents (Ahmad Farouk \& Abu Bakar, 2007). In a study on culturally heterogeneous and homogenous communities in Perlis, Kedah, Penang, and Perak, RT fostered unity by organising activities and mediating conflicts (Khairi \& Mior Jamaluddin, 2017). Khairi and Mior Jamaluddin (2017) suggested that it is essential for community-based peacebuilding to begin from the grassroots level to ensure the authenticity of public interest. Building cultural tolerance can be one of the major efforts to build peace within a community.

This study aimed to explore the cultural tolerance values of Malaysians and their experiences of positive relationships and well-being living in diverse communities. The research questions are: (1) What are the cultural tolerance values among the Malaysians based on the attitude components; i.e. Affect, Cognitive, and Behavioural? (2) How are the said values related to positive relationships and well-being in the local communities?

\section{Method and study area}

Participants were $(n=163)$ Malaysians undergraduates from a public university in northern Malaysia. They were 41 males, and 122 females, consisting of 83 ethnic Malay, 69 ethnic Chinese, nine ethnic Indian, and two ethnic 'others.' Most (124) participants were living in 
multicultural communities. They were recruited from a general university (Psychology) course through convenience sampling. The participants who consented to participate were instructed to complete an online survey through the course e-learning. The surveys were completed independently outside the lecture hall. Bonus marks were given as compensation.

The qualitative online survey was written in bilingual English and Malay. The English and Malay language items have been back-translated. The items consisted of demographic background and 13 open-ended short-answer questions. The questions included four cultural tolerance values (Table 1), four positive relationships (Table 2), and five well-being (Table 3) items, inquiring the participants' experience living in local communities. All questions were created by the authors. Data were analysed based on the frequency, the topic of each question, and the connections among the three components.

The ordinal rating scale used in question 1 (Table 1) measured subjective responses of participants' perceived level of cultural tolerance. The rating system is meant to order responses from lowest (1) to highest (10) level of cultural tolerance, which does not fulfil an interval scale requirement.

\section{Results}

The following are findings on cultural tolerance values, positive relationships, and well-being. All participants $(n=163)$ answered every question in all sections. The summary of data and sample transcripts were provided for each question. Transcripts in Malay were translated into English for readability.

\section{Cultural tolerance values}

Table 1 contains a list of cultural tolerance values questions. Cultural tolerance values were analysed from the affect, behavioural and cognitive components, and they were found to be parallel. The following indicates the participants' responses with sample transcripts.

Table 1. Cultural tolerance values questions

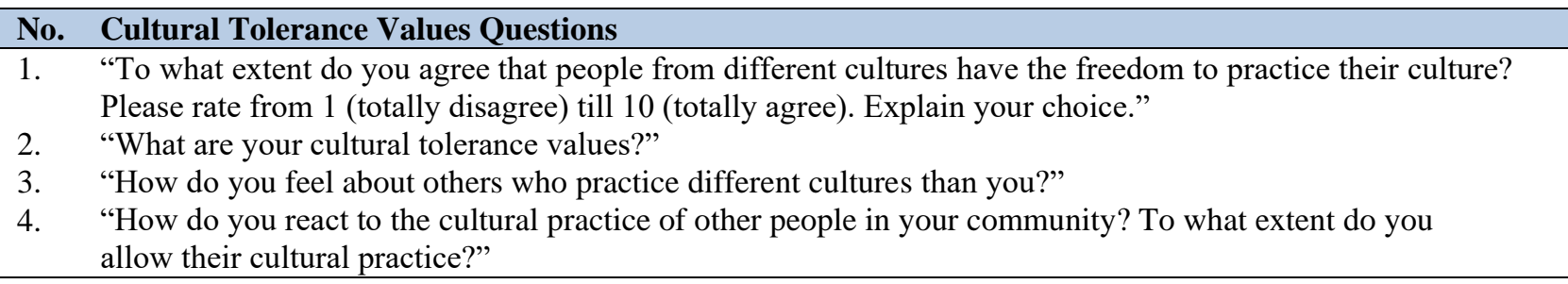

a. Question 1: Rating and level of cultural tolerance

The majority (137) who rated seven and above agreed that people should be allowed to practice their culture. They allowed more freedom towards other cultural practices. Twenty-six (26) rated six and below, and no rating for 1 or 2 . The rest (13) included religions as factors affecting their cultural tolerance values, regardless of the rating. 
Rating $\geq 7$

"Because every person has the right to practice their culture without any fear of being harmed by others."

"I agree. They can practice their respective cultures if not against other religions."

"Everybody is free to practice his/ her religious practice."

Rating $\leq 6$

"Some cultures can be practised, while others can't."

"I don't agree because each culture may clash, which may cause a misunderstanding."

"They have their respective attitude, compliance and religious obligation."

b. Question 2: Personal tolerance values (cognitive)

The majority (102) described high tolerance and open-mindedness, (12) liberal and high tolerance values, and (8) mutual respect. Three (3) participants reported low tolerance values (without explanations), (6) other responses, and (32) void responses.

"High tolerance. I will understand their behaviours when partaking in cultural activities and will not prevent them"

"Liberal and high tolerance. I'll not have any complaint if their culture does not threaten my safety or make the surrounding unpeaceful."

"Conservative, low tolerance."

c. Question 3: Feeling towards others from different cultural backgrounds (affect)

The majority (117) recounted positive emotions, such as respect, curiosity, and happiness towards the practice of others' cultures. Thirty-nine (39) participants reported neutral emotions, such as feeling normal, indifference, and undisturbed by others, and (7) had negative emotions.

Positive emotions

"I will just show my respect to them."

"I feel happy as we can learn many things from people of different cultures, such as their eating behaviour, food choice, the clothes they wear, and so on."

Neutral emotions

"I feel neutral as everyone has the right to practice their culture."

"I don't feel anything if it doesn't affect the value of our community"

Negative emotions

"I feel that I can't understand"

"Ifeel weird"

d. Question 4: Reactions towards others' cultural practices (behavioural)

The majority (97) reacted positively through respect, understanding, acceptance, and freedom.

The rest (66) reacted neutrally or passively, providing their interests or religions were 
undisturbed, having no problem, or being mere observers. Overall, the reactions were either positive or neutral.

"Yes, I allow. It is because I think we should respect the different cultures."

"I just encourage or allow (them) but I did not participate because I'm afraid that it is religion-related."

"If they don't disturb others."

\section{Positive relationships}

For positive relationships and well-being sections, most participants answered the open-ended questions in sentences. They did not explicitly answer the questions with "Yes," "Neutral," or "No" per se. For ease of presentation and summarisation of data, the authors utilised these terms in Tables 2 and 3 to outline the pattern of responses and later provided the explanations and sample transcripts.

The following Table 2 indicates the frequency of participants' responses to their experience of positive relationships living in multicultural communities.

Table 2. Summary of participants' responses to positive relationship questions

\begin{tabular}{|c|c|c|c|c|}
\hline No. & Positive Relationship Questions & \multicolumn{3}{|c|}{ Frequencies } \\
\hline & & Yes & Neutral & No \\
\hline 1. & "Do you think people in your community are connected?" & 141 & 9 & 13 \\
\hline 2. & "Do you feel like you belong in your community?" & 151 & 2 & 10 \\
\hline 3. & "Do you see yourself as part of a bigger group?" & 116 & 8 & 39 \\
\hline 4. & $\begin{array}{l}\text { "Are there any conflicts in your community? Are there intercultural conflicts? How did } \\
\text { people in your community react? How were they managed/ resolved?" }\end{array}$ & 35 & 12 & 116 \\
\hline
\end{tabular}

From Table 2, most participants reported having positive relationships. The following are the participants' responses and sample transcripts.

a. Question 1: Connectedness

The majority (141) recalled the people in their communities were connected through shared activities, frequent interactions, or helping out each other. The minority (9) said "depends" or "sometimes" and (13) were not connected due to a hectic schedule or homogenous community.

"Yes, the people in my community are connected, always helpful towards each other, and understanding respective cultures."

"In my opinion, I feel that only some people in my community are connected."

"We hardly interacted because we rarely meet people from other ethnicities as their number is too few."

b. Question 2: Belongingness

The majority (151) achieved a sense of belonging in their communities through communal activities, shared concerns, and relationships. Two (2) mentioned "sometimes" or "not really," 
with reasons such as preoccupation with personal gadgets. The rest (10) did not achieve a sense of belonging in their communities due to a busy schedule.

"Yes, because I feel like we are a family."

"Not really. I fall under the generation where technology has a major influence in my daily life, so I think I tend to be more occupied with my phone at all times." "No, because I think we do not have much interaction with each other. We are always busy with our assignments or society activities."

\section{c. Question 3: Part of a bigger group}

The majority (116) perceived themselves as part of a bigger group in their communities, regardless of living in heterogeneous or homogenous neighbourhoods. The remaining (8) thought they "need to adapt" or "unsure" and (39) did not see themselves as part of a bigger group.

"Yes, I see myself as part of a bigger group because my group consists of people who practice different cultures in their life."

"Even though my cultural group is the majority group, but we do not leave the minority groups behind"

"No, since we are not connected because we are very busy with our lives, I don't think I'm a part of a bigger group."

d. Question 4: Conflict in communities

Most participants (116) had never encountered any conflict, while (35) witnessed conflicts in their communities, but only (15) reported cultural conflicts. Twenty (20) participants mentioned conflicts unrelated to cultural issues. The remaining (12) neutral participants were unsure or unaware of any conflict.

"No, people always greet each other and are okay."

"Yes, we will try to communicate with each other to solve the problem."

"Maybe there were few conflicts, but they were individual conflict unrelated to cultures. Thus, conflicts could be personally managed."

"I guess conflicts are happening but (I'm) not sure what."

\section{Well-being}

From Table 3, most participants reported a high level of well-being. The five questions on wellbeing were based on PERMA. The following indicates the participants' responses and sample transcripts. 
Table 3. Summary of participants' responses to well-being questions

\begin{tabular}{lllll}
\hline No. & Well-being Questions & \multicolumn{3}{c}{ Frequencies } \\
\hline & & Yes & Neutral & No \\
1. & "How do you generally feel? Do you feel happy?" & 150 & 7 & 6 \\
2. "Are you actively engaged in intercultural activities? & 105 & 15 & 43 \\
3. "Do you have positive relationships with people from a diverse cultural & 154 & 4 & 5 \\
& background in your community?" & 155 & 3 & 5 \\
$4 . \quad$ "Do you think your life is meaningful?" & 92 & 44 & 27 \\
5. "Do you feel that you have achieved something in your life?" & & & \\
\hline
\end{tabular}

\section{a. Question 1: Positive Emotion}

The majority (150) described feeling happy living in harmonious, helpful, respectful, and conflict-free communities. The minority (7) reported feeling "normal" or "neutral" providing they did not negatively affect others, while (6) were unhappy without reasons.

"I am happy and excited about joining and celebrating the different festivals and cultures that are practised by different categories of people."

"No, I feel neutral"

\section{b. Question 2: Engagement}

The majority (105) were involved in intercultural activities, such as visiting and celebrating different cultural festivals. Fifteen (15) participants were only sending wishes or gifting food. The rest (43) were uninvolved due to a lack of activities or invitation to celebrate cultural festivals. They remained passive observers of the celebrations.

\footnotetext{
"Yes. I do visit people from different cultures during festival celebrations."

"If it doesn't clash with my religion."

"I'm not directly involved, but usually, I will give a celebration wishes and send festive food to my neighbours."

"No, because I don't get the chance to celebrate it."
}

\section{c. Question 3: Relationship}

The majority (154) established positive relationships with culturally diverse people in the communities. They preferred to mingle or frequently engaged in university activities that exposed them to diverse people. Meanwhile, (4) participants had no opportunity or an average relationship with others. The rest (5) reported "no" without explanations or homogenous population.

"Yes, I always prefer to have a strong positive relationship with other cultures."

"It's a normal relationship; we are not actively (involved)."

"No, because there is not much diversity." 


\section{d. Question 4: Meaning}

The majority (155) cited meaningful lives with caring friends and family and living in diverse communities. Three (3) participants said "depends" or "unsure" while (5) participants felt that their life was not meaningful (without explanations) or not yet meaningful due to young age.

"I feel that my life is very meaningful surrounded by a caring community even though we are different in terms of religions and cultures."

"I am unsure."

"I'm 23 and all I'm able to do is study so, for now, nope, at least not yet. I'll find a purpose when I can do so."

\section{e. Question 5: Accomplishment}

The majority (92) stated that they had accomplished something in life. Forty-four (44) participants claimed that as undergraduates, they were still working towards achievement. The rest (27) perceived that they had not achieved anything in life.

\footnotetext{
"Yes, but life is full of challenges. I must work towards achieving something new in my life so that my life becomes more meaningful."

"Not yet, still in progress."

"Nope, I feel like I'm not contributing to society."
}

\section{Discussion}

This study set out to answer two research questions. The findings provided some explorations and insights into the cultural tolerance values, positive relationships, and well-being of Malaysian university students. The operational definitions of cultural tolerance, positive relationship, and PERMA for well-being were utilised to assess those elements.

For the first research question, we found that cultural tolerance values were generally positive across components of affect, cognitive and behavioural. For affect, the majority reported positive emotions, such as respect, curiosity, and happiness towards the practice of others' cultures. For cognition, most agreed that people should be allowed to practice their cultures and described themselves as highly tolerant and open-minded. For behaviours, many reacted positively towards others through respect, understanding, acceptance, and freedom. There was a parallel connection between the three components. This concurred with Eagly and Chaiken (1993), whereby tolerance values were formed based on evaluation (positive feelings, thoughts, and behaviours), through exposure with the attitude objects (people from other cultures). Evaluative responding would form a psychological tendency when subsequently encountering the out-group. Such a tendency, once created, would translate into the formation of tolerance attitude/ values (Eagly \& Chaiken, 1995). Hence, participants who reported high tolerance attitude have developed genial feelings, positive thoughts and expressed respectful behaviours/ reactions towards diverse people.

These findings were consistent with previous studies on tolerance in Malaysia whereby participants reported being generally tolerant except for sensitive issues (Abdul Rahman et al., 2015; Abdul Hamid et al., 2016). Our findings provided more evidence demonstrating a high 
level of cultural tolerance among Malaysians. Although inter-ethnic friendships were relatively low, it did not mean that ethnic-relations in Malaysia were bad. Cultural tolerance represented another indicator of ethnic relationships in diverse communities and the findings indicated that ethnic relation in Malaysia is good, at least from the perspective of tolerance. These findings highlighted the importance of looking at more comprehensive indicators of ethnic relations in Malaysia.

The themes of tolerance found in this study were also consistent with themes described in Abdul Hamid et al.'s (2016) study whereby aspects of socialisation, acceptance, neighbourliness, respect, and comfort living in a diverse community were highlighted. These themes demonstrated that Malaysians from different ethnic groups shared similar cultural tolerance values that may have contributed to relatively peaceful co-existence among diverse people. Future studies should explore other values and how they were fostered in the past and more importantly, in the future.

Cultural tolerance was found to be connected to the participants' religions (Gołębiowska, 2009; Wan Husin et al., 2020), albeit religions were not an intended part of the present research objective. The dynamics of in-group and out-group (Tajfel, 1974) interactions were also affected by religious differences. The religious values of several participants influenced their cultural tolerance values; the religious values determined their agreement and involvement in intercultural activities due to perceived clashes. This exemplified the vital influence of religions in many intercultural interactions; it was a deeply embedded aspect in many Malaysians' life in multicultural communities (Wan Husin et al., 2020). Gołębiowska (2009) found that people were more accepting of inter-ethnic than inter-religious marriages. Both our findings and Gołębiowska's indicated tolerance for religious differences were stronger and more influential than ethnic differences. Future studies on cultural tolerance should include factors such as religions, to effectively capture the intertwining effects of different factors on cultural tolerance.

To address the second research question, the reported cultural tolerance values were related to positive relationships and well-being in the local communities. High cultural tolerance values were parallel with positive relationships (consistent with Al Zu'abi, 2018; Abdul Rahman et al., 2015; Abdul Hamid et al., 2016), and well-being. Many participants claimed to be respectful towards the rights and freedom of others' cultural practices, which allowed intercultural relationships to flourish. They reported connectedness, belongingness, group membership, and low intercultural conflict. Many also experienced well-being and peaceful coexistence in communities through happiness, active engagements in intercultural activities, good relationships with diverse people, meaningful life, but low achievements. Most undergraduates equated achievements to career successes and they are yet to achieve it.

Some exceptions included those with decent tolerance values having low positive relationships due to minimum interaction, low friendship, participation, or engagement in intercultural activities. They did not necessarily form a negative relationship. Some cited a hectic schedule, preoccupation with university activities and personal gadgets, living arrangement that prevented interactions with neighbours, lack of intercultural activity or invitation, and low diversity in the community. They might utilise passive approaches to cultural tolerance or intercultural relationships. Others reported being a part of a bigger group because their ethnicities were the majority group. This indicated a deeper nuance to positive relationships in multicultural communities. Further study should explore the connection between an active or passive approach to intercultural relationships and cultural tolerance.

Cultural tolerance values, positive relationships and well-being were not always parallel. Some reported low positive relationships (low sense of belonging and group membership) and 
yet experienced good well-being (positive emotion). Their well-being may be derived from other life aspects. As young undergraduates, they may still be exploring their life purposes, academic, and career aspirations, (see responses under "Meaning" and "Achievement"). These and other factors may have a stronger influence on their well-being. In contrast, a small number cited low well-being (neutral/ negative emotion, low engagement, and low achievement). Apart from cultural tolerance and positive relationships, these undergraduates might face more pressing matters that influenced their well-being, such as academic-related concerns and commitments. Future research should fine-tune the operational definitions of positive relationships and wellbeing specific to Malaysian undergraduates living in multicultural communities.

Unlike the past study (Khairi \& Mior Jamaluddin, 2017), the cultural tolerance values, positive relationships, and well-being data were collected directly from the grassroots level, i.e., the residents instead of key players to maintain the authenticity of the public interest.

This study offered deeper insights and nuances on cultural tolerance values and its connection with positive relationships and well-being in multicultural communities among the Malaysian undergraduates.

\section{Implications}

This study provided some evidence of cultural tolerance among young people in Malaysia through systematic operational definitions and measurements. The findings on positive relationships and PERMA well-being in multicultural communities could bridge certain literature gaps in positive psychology, which were previously lacking. It highlighted the importance of cultural tolerance in contributing to thriving communities.

It is important to explore cultural tolerance further, particularly in multicultural societies like Malaysia. Cultural tolerance should be viewed as part of the societal strengths; thus we need to understand how it can be built further. Culturally-appropriate intervention programs aimed to promote cultural tolerance should be designed and tested. The findings of this study suggest that people are more or less ready for such programs. They can strengthen existing positive relationships, turning them into more meaningful connections and improve well-being. This can contribute towards a more unified Malaysia, but one that still allows for cultural diversity to flourish.

\section{Limitations}

There are several limitations related to this study. Firstly, the sample of university students may not be representative of the entire Malaysian population. Future studies should consider a more extensive sample that can represent a broader range of Malaysian population. Secondly, this study relied heavily on self-report data. Capturing and measuring attitudes can be quite complex (Lauer, 1971). Self -reported attitude might not indicate hidden, implicit components and may not be translated into actions or behaviours. Despite efforts to accurately assess attitude, social desirability bias may still be an issue. Future studies should employ a more sophisticated method to minimise social desirability bias. Data triangulation and implicit measurements may be added to the existing measurements to reduce biases. Quantitative studies may also be conducted to test the relationships between cultural tolerance, positive relationships, and community well-being, thus providing the much-needed empirical evidence for research in positive psychology. 


\section{Conclusion}

This study provides useful research findings related to Malaysians' cultural tolerance values, people's relationships within multicultural communities and community well-being. It highlights the needs to further study communities' strengths such as cultural tolerance, in the context of diverse societies such as Malaysia.

\section{Acknowledgement}

The first author is an international student and a $\mathrm{PhD}$ Research Fellow supported by the Universiti Sains Malaysia Fellowship scheme. The authors declare that the research was conducted in the absence of any commercial or financial relationships that could be construed as a potential conflict of interest.

An earlier version of this manuscript was published in the 3rd USM-International Conference on Social Sciences 2019 proceeding.

\section{References}

Abdul Hamid, A. S., Ahmad Marzuki, N., Ahmad, N. A., \& Ishak, M. S. (2016). Social capital and community cohesion: The constitution of community social capital in Malaysia. International Review of Management and Marketing, 6(8S), 108-112.

Abdul Rahman, A. A., Ahmad, A. R., Awang, M. M., \& Ahmad, J. (2015). Pembinaan dan pengesahan instrumen bagi mengukur amalan patriotisme dan toleransi kaum belia pelbagai kaum. In Mahdum, S. S. Achmad, D. A. Natuna, Suarman, A. R. Ahmad, \& M. H. Mohd Yasin (Ed.), Proceeding 7th International Seminar on Regional Education: Educational community and cultural diversity. 3, pp. 39-56. Riau, Indonesia: Universitas Riau Press.

Ahmad Farouk, A. F., \& Abu Bakar, M. Z. (2007). State-induced social capital and ethnic integration: The case of rukun tetangga in Penang, Malaysia. Kajian Malaysia, 25(1), 4160.

Ahmad Sabri, A. Z., \& Mohammad, N. A. (2016). Relationship between working sector and participation towards rukun tetangga activities in northern state of Malaysia. International Journal of Research in Economics and Social Sciences, 6(5), 209-216.

Ahmad, F., Salman, A., Rahim, S. A., Pawanteh, L., \& Ahmad, A. L. (2013). Interethnic tolerance among multiethnic youth. Journal of Asian Pacific Communication, 23(2), 275290. doi:10.1075/japc.23.2.08ahm

Al Zu'abi, A. (2018). Tolerance in Arab societies. Journal of Asian and African Studies, O(00), 118. doi:10.1177/00219096187625120021909618762512

Chang, P. K., \& Kho, S. N. (2017). A reflection of national integration process and the role of media in Malaysia. Jurnal Komunikasi: Malaysian Journal of Communication, 33(1), 395-405. Retrieved from http://ejournals.ukm.my/mjc/article/view/17013/7725

Diener, E., Oishi, S., \& Lucas, R. E. (2009). Subjective well-being: The science of happiness and life satisfaction. In S. J. Lopez, \& C. R. Snyder (Eds.), Oxford handbook of positive psychology (pp. 187-194). New York: Oxford University Press, Inc. 
Eagly, A. H., \& Chaiken, S. (1993). The psychology of attitudes. Fort Worth, TX: Harcourt Brace Jovanovich College Publishers.

Eagly, A. H., \& Chaiken, S. (1995). Attitude strength, attitude structure, and resistance to change. In R. E. Petty, \& J. A. Krosnick (Eds.), Attitude strength: Antecedents and consequences (Vol. 4, pp. 413-432). New York \& London: Psychology Press.

Gołębiowska, E. (2009). Ethnic and religious tolerance in Poland. East European Politics and Societies, 23(3), 371-391.

Haque, M. S. (2003). The role of the state in managing ethnic tensions in Malaysia: A critical discourse. American Behavioral Scientist, 47(3), 240-266. doi: $10.1177 / 0002764203256186$

Hirschman, C. (1987). The meaning and measurement of ethnicity in Malaysia: An analysis of census classification. The Journal of Asian Studies, 46(3), 555-582. doi:10.2307/2056899

KAJIDATA Research. (2017). Kajian persepsi rakyat dalam membantu usaha kerajaan bagi merangka transformasi nasional 2050. Retrieved from: http://kajidata.com/resources/2017/05/REPORT-PERPADUAN-KESEJAHTERAANTN50.pdf

Kastel, Z. (2012). Positive relations between members of groups with divergent beliefs and cultures. In S. Roffey (Ed.), Positive relationships: Evidence based practice across the world (pp. 245-259). Springer Science Business Media B.V. doi:10.1007/978-94-0072147-0_1

Keyes, C. L. (1998). Social well-being. Social Psychology Quarterly, 61(2), 121-140. doi: $10.2307 / 2787065$

Khairi, A., \& Mior Jamaluddin, M. K. (2017). Community-based peacebuilding in Malaysia: Penang experience. In S. Ladiqi, I. S. Wekke, \& C. Seftyono (Eds.), Religion, state and society: Exploration of Southeast Asia (pp. 151-165). Indonesia: Universitas Negeri Semarang.

Larson, J. S. (1993). The measurement of social well-being. Social Indicators Research, 28, 285-296. doi:10.1007/BF01079022

Lauer, R. H. (1971). The problems and values of attitude research. Sociological Quarterly, 12(2), 247-252.

Lee, H. A. (2017). Fault lines-and common ground-in Malaysia's ethnic relations and policies. ISEAS Perspective, 63(1), 1-9.

Lopez, S. J., \& Gallagher, M. W. (2009). A case for positive psychology. In S. J. Lopez, \& C. R. Snyder (Eds.), Oxford handbook of positive psychology (pp. 3-6). New York: Oxford University Press, Inc.

Ooi, S. H., \& Hashim, I. H. (2018). Elements of positive relationships among Facebook users. Geografia: Malaysian Journal of Society and Space, 14(4), 250-261. doi:10.17576/geo2018-1404-20

Roffey, S. (2012). Introduction to positive relationships: Evidence-based practice across the world. In S. Roffey (Ed.), Positive relationships: Evidence based practice across the world (pp. 1-15). Netherland: Springer Science Business Media B.V. doi:10.1007/97894-007-2147-0_1

Seligman, M. E. (2011). Flourish: A visionary new understanding of happiness and well-being. New York: Atria.

Seligman, M. E., \& Csikszentmihalyi, M. (2000). Positive psychology: An introduction. American Psychologist, 5-14. doi:10.1037//0003-066X.55.1.5 
Snyder, C. R., Lopez, S. J., \& Pedrotti, J. T. (2011). Positive psychology: The scientific and practical explorations of human strengths (2nd ed.). California CA: Sage Publications.

Tajfel, H. (1974). Social identity and intergroup behavior. Social Science Information, 13, 65-93. doi:10.1177/053901847401300204

The National Department of Culture and Arts (JKKN). (2018). Malaysian community. Retrieved from http://www.jkkn.gov.my/en/malaysian-community

Verkuyten, M. (2010). Multiculturalism and tolerance: An intergroup perspective. In R. J. Crisp (Ed.), The psychology of social and cultural diversity (Vol. 10). John Wiley \& Sons.

Wan Husin, W. N., Abdul Halim, N., \& Zul Kernain, N. F. (2020). Students' perceptions on ethnic tolerance in Malaysia: A study in three public universities. Ethnicities, O(0), 1-22. doi: $10.1177 / 1468796820951991$ 